\title{
The Risk of Uterine and Ovarian Cancer for Different Formulations of Hormone Therapy (HT)
}

\author{
Thorsten Raff ${ }^{1}$, Jürgen C. Dinger ${ }^{2}$, Lothar A.J. Heinemann ${ }^{*}, 2$, Sabine Möhner ${ }^{2}$ and Do Minh Thai ${ }^{2}$ \\ ${ }^{1}$ II. Medizinische Klinik, Universitätsklinikum Schleswig-Holstein, Campus Kiel, Chemnitzstraße 33, 24116 Kiel, \\ Germany \\ ${ }^{2}$ Centre for Epidemiology \& Health Research Berlin, Invalidenstr. 115, 10115 Berlin, Germany
}

\begin{abstract}
Little has been published about the impact of different HT formulations or ways of administration on gynecological cancer risk.

Two population-based case-control studies in collaboration with regional cancer registries and tumor centers in Germany were performed.

Some 777 cases of ovarian cancer (OvC) and 1026 cases of uterine corpus cancer (UC) were compared with 3211 and 3668 matched controls for $\mathrm{OvC}$ and $\mathrm{UC}$, respectively. The adjusted odds ratios for risk of cancer were $0.7(0.6-0.9)$ and $0.8(0.7-0.99)$ for OvC and UC for ever $v s$ never use of HT. No clinically relevant trends for OvC and UC risk were observed with increasing duration of HT or with time since first/last use for ever or current use, in all and in postmenopausal women.

Oral, transdermal, and other ways of HT administration were not associated with increased OvC or UC risk: nonsignificant adjusted ORs ranged between 0.6 and 1.3. Sequential and continuous-combined HT formulations showed reduced risk of $\mathrm{OvC}$ and $\mathrm{UC}$, predominantly non-significant. This was similar for different types of estrogens and progestins. Combinations of CEE and MPA showed no other OvC/UC risk than combinations without CEE an MPA.

In this study, HT use was not associated with an increased risk of OvC or UC and did not vary markedly among different HT formulations (estrogens, progestins, oral, and transdermal administration). However, small numbers and other limitations suggest cautious interpretation.
\end{abstract}

Keywords: Ovarian cancer, uterine cancer, cancer risk, case-control study, hormone therapy, epidemiology.

\section{INTRODUCTION}

There have been many complex discussions surrounding the role of steroid hormone formulations since their introduction as treatment, which point to both benefits and risks in short and long-term use [1]. Hormone therapy (HT) became a hot issue with the publication of the Women's Health Initiative (WHI) Study $[2,3]$.

We have shown no increased risk for OvC or UC cancers in our own publications, and in fact even weak evidence for a reduced risk in young women using oral contraceptives $[4,5]$.

Many earlier studies reported no significantly increased or decreased risk of ovarian cancer for ever use of HT [613]. The same applies for the risk of UC with use of opposed HT [14-18]. The WHI study reported no significantly increased risk of ovarian or uterine cancer $[2,3]$ but only for preparations containing conjugated equine estrogens. Recently Beral et al. [19] published data from the Million Women Study that suggests current users of HT have a

*Address correspondence to this author at the Centre for Epidemiology \& Health Research Berlin, Invalidenstr. 115, 10115 Berlin, Germany; Tel: +49.30.94510124; Fax: +49.30.94510126;

E-mail: heinemann@zeg-berlin.de significantly increased risk of $\mathrm{OvC}$ but not past users. An extensive review in the recent IARC Monograph of 2008 [20] demonstrated that long-term use of HT was associated with a slightly increased or decreased risk of OvC, i.e. significantly or non-significantly across different publications. This was similar concerning use of continuous-combined HT and endometrial cancer. For HT with cyclically added progestins the relative risk of $\mathrm{UC}$ was significantly higher. But the debate about the risk of $\mathrm{OvC}$ and $\mathrm{UC}$ associated with HT use seems still open, and in particular little is known about the relative merits or risks of different progestins and ways of administration for either OvC or UC [21].

This publication presents data on ovarian and uterine corpus cancer risk associated with ever and current use of HT of different preparations and administrations in all age groups and postmenopausal women.

\section{MATERIALS AND METHODOLOGY}

The study method has been published earlier [21]. In brief: The objective of this study was to analyze possible differences in risk for two gynecological cancers associated with different HT formulations using a case-control design in collaboration with German cancer registries and tumor centers (see acknowledgements). The population covered was defined by the location of the participating cancer registries/tumor centers, i.e. in Northern Germany (Hamburg, 
Schleswig-Holstein, Berlin) and Central Germany (Zwickau, Chemnitz, Erfurt, Gera, Suhl).

Approvals were obtained (Ethical Committees; Office of Data Privacy). Constraints imposed by ethical and data privacy rules suggested that the tumor registries should identify cases without providing names/addresses and should facilitate contact with cases directly or via the treating physicians (including posting questionnaires). There was only one letter to living cancer cases asking for participation and providing the self-administered questionnaire, i.e. no reminder was sent in case of non-response. The number of diseased cases or number of non-responders was not provided to the investigators who received only the completed questionnaires from responders.

The lifetime history of exposure to sex steroid hormones was recorded by month and year of exposure (type, brand name). This information was compiled on the basis of selfreported information by the women (see below).

Eligible cases were histologically confirmed malignant neoplasm of the ovary (ICD 10: C56) and of the corpus uteri (ICD 10: C54), i.e. in accordance with the definition from the IARC Cancer Registry [23], diagnosed between 2000 and 2004 in women of all age groups. At the time of the intended interview, subjects had to be alive and in sufficiently good condition (decided by physicians or tumor centers/registries) and willing to participate in the study, i.e. to complete the questionnaire. This information was not given to the investigators (see above).

For ovarian cancer, a potential total of 911 cases who had been identified and contacted by the tumor centers/registries and who were willing to participate then sent the completed questionnaires back. But only $777 \mathrm{OvC}$ cases could be used for the analysis because 134 cases were excluded for different reasons: in 15 cases the diagnosis was not fully confirmed, and 119 had another cancer in the same time frame as OvC. The relevant information for UC cases was: 1148 UC cases returned completed questionnaires. $1026 \mathrm{UC}$ cases could be analyzed and 122 cases were excluded: 21 were not fully confirmed diagnoses and 101 had another cancer in the same time frame as UC. As the cancer of the uterine corpus most likely to be affected by HT due to its hormone sensitivity, endometrial carcinoma constitutes about $80 \%$ of all uterine corpus cancers (for review see Clement and Young, $A d$ vances in Anatomic Pathology, 9(3):145-84, 2002). We therefore abstained from subgroup analysis based on the non-reviewable registry data concerning histological subtype.

Up to five eligible controls (with uterus and ovary) were matched for each cancer case in terms of age (same year of birth +/- two years) and area of residence (same state/Bundesland) by using a large, population-based pool of women [22]. Of a total of 18,898 potential controls, we matched 3211 controls for $777 \mathrm{OvC}$ cases and 3668 controls for $1026 \mathrm{UC}$ cases.

\section{Data Collection, Variables and Database Preparation}

Time-related information on lifetime history of hormone use as well as data on reproductive life, lifestyle patterns, conditions/diseases, and some other factors were obtained via a self-administered questionnaire. No visual aids were used such as lists of available hormone preparations or pictures of packages. It is our experience that visual aids are mainly helpful if explained/used by interviewers in face-toface interviews, i.e. they might be useless or dangerous in self-completed questionnaires.

HT preparations ever or currently used were classified according to the route of administration (oral, transdermal, other), type of combination (sequential, continuouscombined), estrogen type (estradiol [E2], conjugated equine estrogens [CEE]), and progestin type (norethindrone acetate [NETA], norgestrel $[\mathrm{NG}]$, levonorgestrel $[\mathrm{LNG}]$, medroxyprogesterone acetate [MPA], medrogestone, cyproterone acetate [CPA], and dydrogesterone). The numbers for other progestins were too small to calculate meaningful risk estimates.

These HT categories are not mutually exclusive for analysis of ever use. Therefore, comparison of risk estimates across exposure groups of ever use can be used only as a first impression as to whether there are substantial differences or not. We also refrained from defining HT categories in terms of "longest used during lifetime" because of the arbitrary character of this decision and the problem of what "longest" might mean across different HT formulations and modes of administration.

We distinguished in the analyses between four subgroups of cancer cases and controls: all women, women in the postmenopausal phase, and this for ever users and current users of HT.

It was not always clear if a woman is in the postmenopausal phase or not. Post-menopause was assumed when the women reported permanent cessation of menstruation. But if this information was missing or unclear or if the woman was currently taking HT, menopause was assumed if her age was over 52 years.

\section{Index Dates}

An index date was introduced to limit a possible protopathic bias. We focused on a lag-time of 0.5 years before diagnosis in order to avoid the possible effect of information related to a perceived $\mathrm{OvC}$ or UC risk immediately preceding the final cancer diagnosis.

\section{The Analytic Model}

Conditional logistic regression was used as primary analysis. Crude and adjusted odds ratios (OR) were reported with $95 \%$ confidence intervals $(95 \% \mathrm{CI})$. Adjustment variables were BMI, family history of ovarian cancer, childbearing history, age at first live birth, duration of breastfeeding, age at menarche, OC use, and education. Missing values of adjustment variables were rare but if so they were imputed to allow the analysis. For sub-group analyses of HT categories, we additionally adjusted for age and residency because the matching effect might be lost in individual subgroups.

Moreover, we refrained from complex adjustment in HTsubgroup analyses to prevent unstable risk estimates. In addition, a cell suppression rule was applied if any cell of the "two-by-two" table contained fewer than 5 women, i.e. no odds ratio was calculated then. 
We analyzed the impact of duration of HT use compared to never use (categories: $<2$ years, 2-4 years, 5-7 years, and $8+$ years), and similarly for the time elapsed from first HT use to the manifestation of cancer (1-4 years, 5-9 years, 1014 years, $15+$ years) as well as for the time since last use (12 years, 3-4 years, and 5+ years ago). Short use (less than 1 year) might be differently recalled by women with cancer versus those without cancer (particularly if longer ago). used.

The statistical packages SAS 9.1 and STATA 8.0 were

\section{RESULTS}

\section{Case/Non-Case Characteristics}

Table 1 shows the OvC and UC cases and matched controls with respect to a list of potential risk factors. Many parameters with significant association were found for $\mathrm{OvC}$ and UC risk, respectively: Age over 50 years $(\mathrm{OR}=2.1$ and $\mathrm{OR}=8.1$ for $\mathrm{OvC}$ and $\mathrm{UC})$, high educational level $(\mathrm{OR}=0.8$ and $\mathrm{OR}=0.7)$, higher age at menarche $(\mathrm{OR}=0.9$ (non-sign.) and 0.7$)$, ever pregnant $(\mathrm{OR}=0.4 / \mathrm{OR}=0.4)$, number of children $(\mathrm{OR}=0.8 / \mathrm{OR}=0.8)$, ever breast feeding $(\mathrm{OR}=0.4$
/ $\mathrm{OR}=0.3)$, ever $\mathrm{OC}$ use $(\mathrm{OR}=0.4 / \mathrm{OR}=0.3)$, family history of the respective cancer $(\mathrm{OR}=4.8 / \mathrm{OR}=2.1)$.

Most of these variables were significant effect modifiers of the association between HT exposure and gynecological cancer risk.

\section{Ever, Current vs Never HT Use}

All risk estimates for OvC and UC cancer were analyzed for ever and current users of HT, i.e. for all women and postmenopausal women. In all subgroups, the results pointed toward reduced risk (Table 2) ranging from OR 0.7 to 0.9 .

The OvC risk was significantly reduced for HT ever and current use in all and post-menopausal women.

A significantly reduced risk of UC was observed for ever use in the subgroup of all women; the risk estimates of other subgroups were non-significantly reduced.

\section{Time-Related Exposure}

Table 2 also shows results of the analyses stratified by duration of HT use. Most but not all point estimates for risk

Table 1. Description of Ovarian and Uterine Corpus Cancer Cases and Matched Controls: Overview of Variables Discussed as Risk Factors for Cancer. Risk of Ovarian and Uterine Cancer Related to Selected Demographic, Physical, Reproductive Variables (Adjusted Odds Ratios (95\% Confidence Interval))

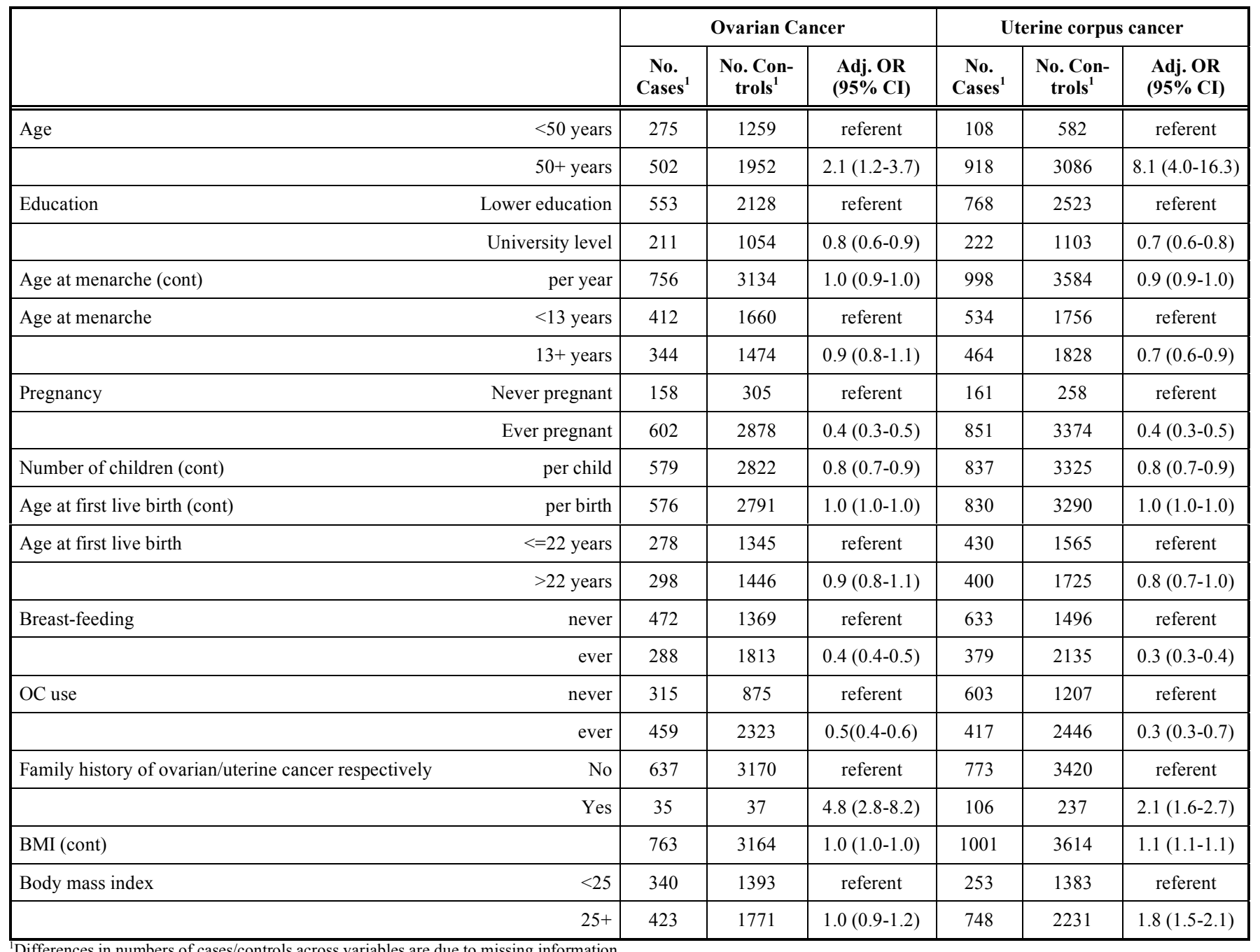


Table 2 Risk of Ovarian and Uterine Corpus Cancer and HT use: Ever and Current Use of HT vs Never Use in All and Postmenopausal Women

\begin{tabular}{|c|c|c|c|c|c|c|c|c|}
\hline & \multicolumn{4}{|c|}{ Ovarian Cancer } & \multicolumn{4}{|c|}{ Uterine Corpus Cancer } \\
\hline & e-case ${ }^{1}$ & e-ctrl. ${ }^{1}$ & $\begin{array}{l}\text { All Cases: } \\
\text { Adj. OR } \\
\text { (95\% CI) }\end{array}$ & $\begin{array}{c}\text { Postmenopausal Cases: } \\
\text { Adj. OR } \\
\text { (95\% CI) }\end{array}$ & e-case ${ }^{1}$ & e-ctrl. ${ }^{1}$ & $\begin{array}{l}\text { All Cases: } \\
\text { Adj. OR } \\
(\mathbf{9 5 \%} \text { CI) }\end{array}$ & $\begin{array}{c}\text { Postmenopausal Cases: } \\
\text { Adj. OR } \\
(95 \% \text { CI })\end{array}$ \\
\hline Ever Use of HT & 238 & 1048 & $0.7(0.6-0.9)$ & $0.7(0.5-0.8)$ & 347 & 1637 & $0.8(0.7-1.0)$ & $0.8(0.7-1.0)$ \\
\hline \multicolumn{9}{|l|}{ Duration of Use ${ }^{2}$} \\
\hline$<2 \mathrm{yrs}$ & 58 & 202 & $0.8(0.5-1.1)$ & $0.8(0.5-1.2)$ & 89 & 272 & $1.3(1.0-1.8)$ & $1.5(1.1-2.0)$ \\
\hline $2-4 \mathrm{yrs}$ & 45 & 208 & $0.8(0.5-1.1)$ & $0.6(0.4-1.0)$ & 78 & 355 & $0.9(0.6-1.2)$ & $0.9(0.6-2.0)$ \\
\hline $5-7 \mathrm{yrs}$ & 46 & 254 & $0.6(0.4-0.9)$ & $0.5(0.3-0.7)$ & 54 & 383 & $0.5(0.4-0.7)$ & $0.5(0.4-0.8)$ \\
\hline $8+\mathrm{yrs}$ & 89 & 384 & $0.8(0.6-1.0)$ & $0.8(0.7-1.0)$ & 126 & 627 & $0.7(0.5-0.7)$ & $0.7(0.7-1.0)$ \\
\hline \multicolumn{9}{|l|}{ Time Since First Use ${ }^{2}$} \\
\hline $1-4 \mathrm{yrs}$ & 92 & 457 & $0.7(0.5-0.9)$ & $0.6(0.4-0.8)$ & 132 & 601 & $1.0(0.8-1.3)$ & $1.1(0.8-1.4)$ \\
\hline $5-9$ yrs & 82 & 350 & $0.8(0.6-1.0)$ & $0.7(0.5-0.9)$ & 133 & 608 & $0.8(0.6-1.0)$ & $0.8(0.6-1.0)$ \\
\hline $10-14$ yrs & 40 & 149 & $0.7(0.5-1.1)$ & $0.7(0.5-1.1)$ & 61 & 278 & $0.8(0.6-1.2)$ & $0.9(0.6-1.3)$ \\
\hline $15+\mathrm{yrs}$ & 24 & 92 & $0.9(0.5-1.5)$ & $0.8(0.5-1.4)$ & 21 & 150 & $0.5(0.3-0.8)$ & $0.5(0.3-0.8)$ \\
\hline Current Use of HT & 142 & 602 & $0.8(0.6-1.0)$ & $0.7(0.5-0.9)$ & 175 & 791 & $0.9(0.7-1.2)$ & $0.9(0.7-1.2)$ \\
\hline \multicolumn{9}{|l|}{ Duration of Use ${ }^{2}$} \\
\hline$<2 \mathrm{yrs}$ & 13 & 56 & $0.7(0.3-1.5)$ & $0.6(0.2-1.7)$ & 14 & 55 & $1.0(0.5-2.1)$ & $1.1(0.5-2.5)$ \\
\hline $2-4$ yrs & 24 & 97 & $0.9(0.5-1.5)$ & $0.6(0.3-1.3)$ & 41 & 134 & $1.6(1.0-2.5)$ & $1.5(1.0-2.5)$ \\
\hline $5-7 \mathrm{yrs}$ & 36 & 163 & $0.8(0.5-1.2)$ & $0.5(0.3-0.9)$ & 31 & 216 & $0.5(0.3-0.9)$ & $0.6(0.3-0.9)$ \\
\hline $8+y r s$ & 69 & 286 & $0.8(0.6-1.2)$ & $0.8(0.6-1.2)$ & 89 & 386 & $0.9(0.6-1.3)$ & $0.9(0.6-1.3)$ \\
\hline \multicolumn{9}{|l|}{ Time Since First Use $^{2}$} \\
\hline $1-4$ yrs & 50 & 292 & $0.6(0.4-0.9)$ & $0.47(0.3-0.8)$ & 65 & 360 & $0.9(0.6-1.3)$ & $0.9(0.6-1.3)$ \\
\hline $5-9 \mathrm{yrs}$ & 61 & 197 & $1.0(0.7-1.4)$ & $0.8(0.6-1.3)$ & 70 & 291 & $1.0(0.7-1.4)$ & $0.9(0.6-1.3)$ \\
\hline $10-14 \mathrm{yrs}$ & 23 & 67 & $1.1(0.6-2.0)$ & $1.1(0.5-2.1)$ & 29 & 85 & $1.3(0.7-2.3)$ & $1.4(0.8-2.4)$ \\
\hline $15+\mathrm{yrs}$ & 8 & 46 & $0.8(0.3-2.0)$ & $0.7(0.3-1.8)$ & 11 & 55 & $0.6(0.2-1.4)$ & $0.6(0.3-1.4)$ \\
\hline
\end{tabular}

Conditional logistic regression analysis [Odds ratios (OR) and 95\% confidence intervals]; adjustment for BMI, family history of uterine cancer, childbearing history, age at first live birth, duration of breast-feeding, age at menarche, ever OC use, education. Index date $0.5=$ exposure information was not considered 0.5 year prior to cancer diagnosis.

1 E-case, e-ctrl = number of observations for exposed cases and exposed controls.

2 Time variables were rounded.

of $\mathrm{OvC}$ and $\mathrm{UC}$ in ever and current users were lower than unity $(\mathrm{OR}=1.0)$ but often statistically non-significant for all and for postmenopausal women.

There was no meaningful trend showing that longer duration of HT use was significantly associated with change in UC risk for all and post-menopausal women, and for ever and current use. However, there might be a slightly increasing $\mathrm{OvC}$ trend with longer duration of current HT use. This might not be clinically relevant because all risk estimates were under 1.0. Not clear is the meaning of a marginally increased risk for UC that was observed in the first duration of use category ( $<2$ years).

There was also no meaningful temporal trend of risk associated with increasing time since first use, i.e. both for $\mathrm{OvC}$ and UC risk. With the exception of two time categories, most showed decreased ORs, some of which were significantly decreased.

\section{Cancer Risk Across Different HT Formulations}

The aim of the analysis of different HT formulation groups was to provide a crude, visual comparison of $\mathrm{OvC}$ and UC risk estimates across different HT categories. Once again, it should be emphasized that ever-use HT categories are not mutually exclusive.

Table 3 contains risk estimates for $\mathrm{OvC}$ and $\mathrm{UC}$ (OR and $95 \%$ confidence interval) by HT formulations and ways of administration. Most of the risk estimates for both gynecological cancers were lower than unity $(<1.0)$, although not all are statistically significant in the subgroups of all and postmenopausal ever and current HT users.

The oral route of administration was dominant among our study participants. Oral HT ever use showed a significantly decreased $\mathrm{OvC}$ and $\mathrm{UC}$ risk associated with hormone use in all and postmenopausal women. 
Table 3 Risk of Ovarian Cancers Associated with Different Categories of HT Formulation or Administration (Ever Used HT)

\begin{tabular}{|c|c|c|c|c|c|c|c|c|}
\hline \multirow[b]{2}{*}{ Formulation Categories } & \multicolumn{4}{|c|}{ Ovarian Cancer } & \multicolumn{4}{|c|}{ Uterine Corpus Cancer } \\
\hline & e-Case & e-ctrl. & $\begin{array}{l}\text { All Cases: } \\
\text { Adj. OR } \\
(95 \% \text { CI) }\end{array}$ & $\begin{array}{l}\text { Postmenopausal } \\
\text { Cases: Adj. OR } \\
\text { (95\% CI) }\end{array}$ & e-Case & e-ctrl. & $\begin{array}{l}\text { All Cases: } \\
\text { Adj. OR } \\
\text { (95\% CI) }\end{array}$ & $\begin{array}{l}\text { Postmenopausal } \\
\text { Cases: Adj. OR } \\
\text { (95\% CI) }\end{array}$ \\
\hline \multicolumn{9}{|c|}{ Route of Administration } \\
\hline oral & 170 & 748 & $0.7(0.5-0.9)$ & $0.6(0.5-0.8)$ & 219 & 1165 & $0.6(0.5-0.8)$ & $0.7(0.5-0.8)$ \\
\hline transdermal & 37 & 210 & $0.5(0.3-0.9)$ & $0.5(0.3-0.9)$ & 86 & 326 & $1.0(0.7-1.4)$ & $1.0(0.7-1.3)$ \\
\hline other & 18 & 101 & $0.6(0.3-1.1)$ & $0.4(0.2-0.9)$ & 35 & 134 & $0.8(0.5-1.4)$ & $0.9(0.5-1.4)$ \\
\hline \multicolumn{9}{|c|}{ Form of Combination } \\
\hline Sequential formulations & 88 & 445 & $0.7(0.5-0.9)$ & $0.6(0.5-0.9)$ & 121 & 667 & $0.6(0.5-0.8)$ & $0.6(0.5-0.9)$ \\
\hline Continuous-combined & 64 & 285 & $0.6(0.4-0.9)$ & $0.6(0.4-0.8)$ & 95 & 475 & $0.7(0.5-0.9)$ & $0.7(0.5-0.9)$ \\
\hline All estrogen + progestin & 134 & 639 & $0.6(0.5-0.8)$ & $0.6(0.4-0.7)$ & 181 & 996 & $0.6(0.5-0.8)$ & $0.6(0.5-0.8)$ \\
\hline \multicolumn{9}{|c|}{ CEE/MPA Combinations } \\
\hline $\mathrm{CEE}+\mathrm{MPA}$ & 8 & 70 & $0.5(0.2-1.0)$ & $0.4(0.2-1.0)$ & 21 & 93 & $0.6(0.3-1.0)$ & $0.6(0.3-1.0)$ \\
\hline CEE or MPA & 73 & 285 & $0.8(0.6-1.1)$ & $0.7(0.5-1.0)$ & 81 & 467 & $0.5(0.4-0.8)$ & $0.6(0.4-0.8)$ \\
\hline No CEE, no MPA & 117 & 546 & $0.6(0.5-0.8)$ & $0.6(0.4-0.8)$ & 177 & 854 & $0.7(0.6-0.9)$ & $0.7(0.6-0.9)$ \\
\hline \multicolumn{9}{|c|}{ Estrogen Type } \\
\hline Estradiol (E2) & 141 & 676 & $0.6(0.5-0.8)$ & $0.6(0.4-0.8)$ & 209 & 1042 & $0.7(0.6-0.9)$ & $0.7(0.6-0.9)$ \\
\hline Conjugated equine estrogens (CEE) & 71 & 302 & $0.7(0.5-1.0)$ & $0.7(0.5-1.0)$ & 83 & 481 & $0.5(0.4-0.7)$ & $0.5(0.4-0.7)$ \\
\hline \multicolumn{9}{|l|}{ Progestin type } \\
\hline Norethindrone acetate (NETA) & 79 & 362 & $0.6(0.4-0.9)$ & $0.6(0.4-0.8)$ & 98 & 560 & $0.7(0.5-0.9)$ & $0.7(0.5-0.9)$ \\
\hline Norgestrel (NG) & 6 & 12 & $1.9(0.5-6.5)$ & n.d. & 7 & 22 & $1.1(0.3-3.8)$ & $1.1(0.3-3.8)$ \\
\hline Levonorgestrel (LNG) & 38 & 205 & $0.6(0.4-1.0)$ & $0.8(0.5-1.3)$ & 65 & 306 & $0.7(0.5-0.9)$ & $0.6(0.4-0.9)$ \\
\hline Medroxyprogesterone acetate (MPA) & 18 & 123 & $0.5(0.3-1.0)$ & $0.5(0.3-1.0)$ & 40 & 172 & $0.7(0.4-1.1)$ & $0.7(0.5-1.1)$ \\
\hline Cyproterone acetate (CPA) & 7 & 25 & $1.1(0.4-2.8)$ & $1.2(0.3-4.1)$ & 5 & 34 & $0.5(0.2-1.5)$ & n.d. \\
\hline Medrogestone & 27 & 136 & $0.6(0.3-0.9)$ & $0.5(0.3-0.8)$ & 29 & 221 & $0.4(0.2-0.6)$ & $0.4(0.2-0.7)$ \\
\hline Dydrogesterone & 6 & 12 & $1.8(0.5-5.9)$ & n.d. & 6 & 19 & $0.9(0.3-3.0)$ & $1.0(0.3-3.1)$ \\
\hline
\end{tabular}

Conditional logistic regression: Odds ratios (OR) and $95 \%$ confidence intervals $(95 \% \mathrm{CI})$; adjusted only for age and residency.

e-cas= exposed cases; e-ctrl= exposed controls; n.d. = no data (cell suppression rule).

Transdermal application and other forms of administration showed mainly non-significant $\mathrm{OvC}$ and UC risk estimates across all subgroups.

Ever use of both sequential and continuous-combined HT formulations showed significantly reduced $\mathrm{OvC}$ and $\mathrm{UC}$ risk estimates across all subgroups including current use.

No obvious or meaningful difference in risk of $\mathrm{OvC}$ and $\mathrm{UC}$ was found between women ever having or currently using $H T$ with $C E E+M P A$ (alone or together) across all subgroups.

No substantial or meaningful differences in OvC and UC risk were observed among the categories with different estrogens progestins across the four subgroups. The point estimates were mainly lower than unity and many statistically insignificant, but often compromised by small numbers. Estrogens and progestins not listed in Table $\mathbf{3}$ were not frequent enough to calculate risk estimates for $\mathrm{OvC}$ and UC (see methods: "cell suppression rule").

\section{DISCUSSION}

Cancer of the ovary and uterine corpus result in substantial morbidity and mortality even though they are not among the most frequent neoplasms: $\mathrm{OvC}$ is the seventh most common female cancer in the ranking worldwide and uterine corpus cancer the eighth most common cancer in women according to an expert review by the American Institute of Cancer Research [24].

For ovarian cancer, these experts suggest that the following parameters play a role as risk factors: Obesity increased risk in some but not all studies; a higher number of pregnancies is associated with reduced risk; and OC use is possibly linked with a lower total number of ovulations [24]. It is also known that most ovarian cancers have estrogen receptors, and therefore a relation with external hormone use could be plausible [25]. However, in a review published in 2002, no satisfactory conclusion about OvC risk related to HT was obtained: five studies found a slightly increased risk but 15 did not observe an increased risk for ovarian cancer associated with HT [26]. 
Table 3a. Risk of Ovarian Cancers Associated with Different Categories of HT Formulation or Administration (Currently Used HT)

\begin{tabular}{|c|c|c|c|c|c|c|c|c|}
\hline \multirow[b]{2}{*}{ Formulation Categories } & \multicolumn{4}{|c|}{ Ovarian Cancer } & \multicolumn{4}{|c|}{ Uterine Corpus Cancer } \\
\hline & e-Case & e-ctrl. & $\begin{array}{l}\text { All Cases: } \\
\text { Adj. OR } \\
\text { (95\% CI) }\end{array}$ & $\begin{array}{l}\text { Postmenopausal } \\
\text { Cases: Adj. OR } \\
\text { (95\% CI) }\end{array}$ & e-Case & e-ctrl. & $\begin{array}{l}\text { All cases: } \\
\text { Adj. OR } \\
(95 \% \text { CI) }\end{array}$ & $\begin{array}{c}\text { Postmenopausal } \\
\text { Cases: Adj. OR } \\
\text { (95\% CI) }\end{array}$ \\
\hline \multicolumn{9}{|l|}{ Route of Administration } \\
\hline oral & 113 & 446 & $0.8(0.6-1.0)$ & $0.7(0.5-0.9)$ & 128 & 581 & $0.7(0.5-0.9)$ & $0.7(0.5-0.9)$ \\
\hline transdermal & 27 & 116 & $0.6(0.3-1.0)$ & $0.6(0.3-1.1)$ & 56 & 154 & $1.3(0.9-2.0)$ & $1.3(0.9-2.1)$ \\
\hline other & 13 & 56 & $0.7(0.3-1.7)$ & $0.6(0.2-1.5)$ & 21 & 67 & $0.8(0.4-1.5)$ & $0.8(0.4-1.6)$ \\
\hline \multicolumn{9}{|l|}{ Form of Combination } \\
\hline Sequential formulations & 61 & 276 & $0.7(0.5-1.0)$ & $0.7(0.4-1.0)$ & 67 & 331 & $0.7(0.5-1.0)$ & $0.7(0.5-1.0)$ \\
\hline Continuous-combined & 48 & 173 & $0.8(0.5-1.2)$ & $0.7(0.4-1.1)$ & 61 & 260 & $0.8(0.6-1.2)$ & $0.8(0.6-1.2)$ \\
\hline All estrogen + progestin & 92 & 387 & $0.7(0.5-0.9)$ & $0.6(0.4-0.9)$ & 105 & 503 & $0.7(0.5-0.9)$ & $0.7(0.5-0.9)$ \\
\hline \multicolumn{9}{|l|}{ CEE/MPA Combinations } \\
\hline $\mathrm{CEE}+\mathrm{MPA}$ & 7 & 51 & $0.6(0.2-1.4)$ & $0.5(0.2-1.3)$ & 17 & 60 & $0.7(0.3-1.3)$ & $0.6(0.3-1.3)$ \\
\hline CEE or MPA & 47 & 182 & $0.8(0.5-1.1)$ & $0.8(0.5-1.2)$ & 46 & 237 & $0.6(0.4-0.8)$ & $0.6(0.4-0.9)$ \\
\hline No CEE, no MPA & 80 & 305 & $0.8(0.5-1.1)$ & $0.6(0.4-0.9)$ & 100 & 404 & $0.8(0.6-1.1)$ & $0.8(0.6-1.1)$ \\
\hline \multicolumn{9}{|l|}{ Estrogen Type } \\
\hline Estradiol (E2) & 99 & 402 & $0.7(0.6-1.0)$ & $0.7(0.5-0.9)$ & 123 & 520 & $0.8(0.6-1.1)$ & $0.8(0.6-1.1)$ \\
\hline Conjugated equine estrogens (CEE) & 49 & 206 & $0.8(0.5-1.1)$ & $0.8(0.5-1.2)$ & 54 & 258 & $0.6(0.4-0.9)$ & $0.6(0.4-0.8)$ \\
\hline \multicolumn{9}{|l|}{ Progestin Type } \\
\hline Norethindrone acetate (NETA) & 56 & 209 & $0.7(0.5-1.1)$ & $0.7(0.4-1.00)$ & 59 & 276 & $0.8(0.6-1.2)$ & $0.8(0.6-1.2)$ \\
\hline Norgestrel (NG) & 4 & 6 & n.d. & n.d & 5 & 8 & n.d. & n.d. \\
\hline Levonorgestrel (LNG) & 26 & 131 & $0.7(0.4-1.1)$ & $0.8(0.5-1.5)$ & 35 & 162 & $0.7(0.4-1.1)$ & $0.7(0.4-1.1)$ \\
\hline Medroxyprogesterone acetate (MPA) & 12 & 78 & $0.6(0.3-1.2)$ & $0.5(0.2-1.2)$ & 26 & 99 & $0.7(0.4-1.2)$ & $0.7(0.4-1.3)$ \\
\hline Cyproterone acetate (CPA) & 5 & 13 & $\begin{array}{c}1.0(0.31- \\
3.24)\end{array}$ & n.d. & 2 & 14 & n.d. & n.d. \\
\hline Medrogestone & 17 & 92 & $0.5(0.3-0.9)$ & $0.4(0.2-0.9)$ & 16 & 109 & $0.3(0.2-0.7)$ & $0.4(0.2-0.7)$ \\
\hline Dydrogesterone & 5 & 9 & n.d. & n.d. & 3 & 12 & n.d. & n.d. \\
\hline
\end{tabular}

Conditional logistic regression: Odds ratios (OR) and $95 \%$ confidence intervals $(95 \% \mathrm{CI})$; adjusted for age and region.

e-case $=$ exposed cases; e-ctrl $=$ exposed controls; n.d. $=$ no data (cell suppression rule) .

We found consistency with the literature concerning risk factors for OvC. Ever being pregnant $(\mathrm{OR}=0.39)$ and $\mathrm{OC}$ use $(\mathrm{OR}=0.46)$ showed the expected reduction of $\mathrm{OvC}$ risk. Similar results showing significantly reduced risk for ovarian cancer were reported by a large Danish case-control study (554 cases and 1566 controls) [27]: ever pregnant $(\mathrm{OR}=0.4)$, with increasing number of pregnancies $(\mathrm{OR}=0.9)$, older age at last pregnancy ( $\mathrm{OR}=0.9$ per 5 years), and ever use of OCs $(\mathrm{OR}=0.7)$.

For uterine corpus cancer, the above-mentioned expert panel considered all potential risk factors, including among others a prolonged high internal or external exposure to estrogens when unopposed by progestins [24]. Thus, early age at menarche or late menopause may constitute an increased risk, whereas pregnancy and high parity reduce the risk. This confirms what we observed. The mechanism by which hormonal factors may affect carcinogenesis at different gynecological sites was considered unclear [24]. A newer publica- tion [28] suggested some explanations for different proliferative activity of different hormone formulations depending on different estrogen and other receptors differently stimulated by HTs.

The similarity of risk factors (including effects of exogenous hormones) in $\mathrm{OvC}$ and $\mathrm{UC}$, and also across more or less all non-communicable diseases is striking and gives rise to speculation about non-specific, non-causal associations with gynecological tumors [29], for example. Given the great potential for residual confounding and bias, even a statistically significant small association might be inconclusive, because such associations could well be situated below reliable resolution levels of the "epidemiological microscope", i.e. it is not possible to discriminate between causation and bias/confounding $[25,29,30]$.

Overall, we found no clinically meaningful OvC risk for ever and current users of HT, and even a significantly decreased OvC risk on the basis of 777 cases of ovarian cancer 
compared with 3211 matched controls. A result with a similar order of magnitude was reported by Hempling 1997 [6], but Beral 2007 [19] reported an increased risk of developing OvC for current users.

Our current case-control study confirms the results of our recently published nested case-control study that showed at least no increased risk of ovarian cancer associated with HT use, although with small numbers [31].

There is still no consensus as to whether a slightly decreased or increased OvC risk is associated with HT use $[7,11,12,13,19,32]$. Some authors report decreased and others increased risk estimates, particularly after long periods of use [8]. A collaborative re-analysis of four European casecontrol studies from 1984 to 1994 [10] was based on relatively small samples of cases in the individual studies $(\mathrm{n}=112,152,971$, and 235 respectively). The authors of this review calculated increased $\mathrm{OvC}$ risk estimates associated with ever use of HT ranging from 1.4 to 1.8 - all but one study were not significant. After pooling the studies, the risk became - as expected - significantly increased due to higher numbers [10]. Many US case-control studies showed no association of HT use with ovarian cancer [9], but others presented some increased ovarian cancer risk $[25,33,34]$. Discussion has suggested that this difference could be due to different user patterns or types of HT, or simply a chance finding notwithstanding the often discussed problem of statistical significance and clinical relevance [10]. No significantly increased risk of ovarian cancer was reported in the WHI [2,3] and HERS studies [35]; however, the numbers were too small to draw conclusions.

We observed no meaningful trend in the OvC risk with increasing duration of use in ever users and also in the subgroup of postmenopausal women. There might be a slightly increasing $\mathrm{OvC}$ risk trend with longer duration in current users of HT. We consider this to be not clinically relevant because all risk estimates are less than 1.0.

The focus of our study, however, was to detect possible differences in OvC risk across different HT formulations or ways of administration in ever or current users. But no meaningful differences were observed. Taken at face value, the point estimates for HT use would be compatible with a decreased risk of ovarian cancer. For some of the progestins, the small numbers prevented conclusions other than no clinically relevant differences being detectable.

We found no clinically meaningful UC risk in users of "estrogen plus progestin" (E+P) hormone treatment, or even a significantly decreased UC risk on the basis of 1026 cases of uterine corpus cancer compared with 3668 matched controls.

In other case-control studies, the relative risk of uterine cancer was usually not increased. In a meta-analysis of 30 studies, opposed estrogen treatment $(\mathrm{E}+\mathrm{P})$ showed little if any risk; i.e. many risk estimates were observed well below 1.0 [36]. Later reviews confirmed the view of no increased risk of endometrial cancer in users of opposed HT [37-39].

In a recent review, case-control and cohort studies have been broadly consistent concerning the risk estimates for endometrial cancer and contraceptive use [40]. In an earlier meta-analysis, however, cohort studies showed a lower risk than case-control studies [36]. Our current case-control study confirms the results of our recently published nested casecontrol study that showed no increased risk of uterine cancer [41].

Moreover and in contrast to breast cancer, no increased risk of uterine corpus cancer was reported in the WHI $[2,13]$ or HERS studies [35]. The Million Women Study [42] found a significantly reduced risk of endometrial cancer in women with last use of continuous combined preparations (RR 0.71 ), and not significantly associated with cyclic combined HT formulations (RR 1.05). We observed for both forms of $\mathrm{E}+\mathrm{P}$ combinations mainly significant reduced risk of UC. This was indirectly supported by a recent Cochrane review which stated that "the addition of progestagens, either in continuous-combined or sequential regimens, helped to prevent the development of endometrial hyperplasia" [43]. Moreover, it was also stressed that particular continuouscombined regimens may have no or even a protective effect on the endometrium [16].

The distribution of UC risk for different HT formulation or administration categories is compatible with the notion that no obvious differences were observed. Almost all point estimates were below unity (1.0). Taken at face value, the point estimates for HT use would be compatible with a decreased risk of uterine corpus cancer. For some of the progestins, the small numbers prevented us from drawing any strong conclusions. It is our understanding, however, that no clinically relevant differences among different progestins were detectable.

\section{Possible Limitations of the Study}

In general, case-control studies like other observational studies are prone to bias and residual confounding. It cannot be excluded that self-selection of cases is a problem in our study. We cannot offer information about non-response or selection of surviving cases by cancer registry/tumor centers due to design. If there is a bias - which we do not assume it might be even differential regarding exposure status. A possible source of recall bias is the use of a self-administered questionnaire without visual aids, although it is our experience that recall is relatively accurate regarding hormone use in women. It is our assumption that the results of our study have not been substantially affected by differential selfselection or recall bias, although we cannot exclude these possibilities.

Analysis of the effect of external hormones on ovarian and uterine corpus cancer must take into account the lag time in cancer development, although it is difficult for observational studies to account sufficiently for time-dependence. Lag time is likely to be long and may vary depending on complex unknown causal mechanisms, and is therefore an issue involving complex, time-dependent risk factors. However, we could not account for the latent period because we had no chance to determine the interval between tumor induction and diagnosis.

Another exposure-related problem is the focus on detecting differences in the risk of $\mathrm{OvC}$ and $\mathrm{UC}$ across different exposure categories, i.e. HT formulations and ways of administration in ever users. These categories were not mutual exclusive since one can use more than one HT with more than one way of administration over a period of years. This 
potential problem seems not to be serious in our study, because a comparison with current HT use, where this problem does not exist, showed conclusions in the same direction.

A less likely but potential source of bias is the diagnostic suspicion bias even for serious diseases such as cancer. Nobody can be sure that early stage tumor cases are equally identified (diagnosed) among HT users and non-users. This, however, would not explain the reduced risk estimates for $\mathrm{OvC}$ and $\mathrm{UC}$ observed. In addition, the possibility cannot be excluded e.g. that the women and/or their physicians were aware of "warning signs" (e.g. bleedings) that may have led to the decision not to use HT in the year prior to final OvC or $\mathrm{UC}$ diagnosis. This exposure indication bias may have worked differentially, i.e. more often in later confirmed cancer cases than in controls. Stratification by index dates (increasing lag times) should have helped us to cope with such a problem.

Moreover, observational studies with "state-of-the-art" performance face an important methodological problem if the observed risk estimates are small. Given the great potential for residual confounding and different undetected forms of bias, even a statistically significant small positive or inverse association cannot be ruled out and the results might be inconclusive. Such small associations could well be situated below reliable resolution levels of the "epidemiological microscope", i.e. it is not possible to differentiate between causation and bias/confounding [14,30].

Therefore, the interpretation of the $\mathrm{OvC}$ and $\mathrm{UC}$ risk estimates observed in our case-control study should be taken with care.

\section{CONCLUSIONS}

Ever and current use of HT was at least not associated with an increased risk of ovarian and uterine corpus cancer, either in all or in post-menopausal women. Obviously, the decreased risk estimates did not vary markedly among different HT subgroups. However, the small numbers and the overlapping nature of the HT formulation subgroups of everuse suggests cautious interpretation. Moreover, there might be differences that were not detectable in our study due to the "limited solution of the epidemiological microscope".

\section{COMPETING INTEREST}

The study was self-funded by the Centre for Epidemiology and Health Research Berlin. No conflict of interest is declared. An earlier case-control study on breast cancer and HT formulations was co-sponsored by a pharmaceutical company: Schering AG Berlin.

\section{AUTHORS' CONTRIBUTIONS}

TR: Involved in the analysis, responsible for writing the manuscript; JCD: contributed to the design of the study and revision of the manuscript, and was involved in the data analysis; LAJH: responsible for the design of the study and prepared the data analysis plan, contributed to revisions of the manuscript; SM: responsible for development of all questionnaires, responsible for the collaboration with the tumor centers as well as quality checks and management of the initial database, contributed to the manuscript; DMT: responsible for data management and final data analysis; contributed to the manuscript.

\section{ACKNOWLEDGEMENTS}

We are particularly thankful for the collaboration by the clinical tumor centers and cancer registries and their commitment and efforts to make this case-control study possible. The key individuals involved were the following:

Südwestsächsisches Tumorzentrum Zwickau:

E. Standke, V. Wulff, C. Matthes

Tumorzentrum Berlin-Buch: G. Morack, H. Lüders

Tumorzentrum Berlin-Charite: V. Budach, J. Bellach, JU Blomer, KJ Winzer, P. Cyganiak

Tumorzentrum Chemnitz: R. Lange, B. Schubotz

Tumorzentrum Erfurt: B. Ulshöfer, H. Göbel

Tumorzentrum Gera: H. Urban, R. Götze

Tumorzentrum Suhl: D. Fröhlich, M. Wackes

Hamburgisches Krebsregister: S. Hentschel, U. Haartje, A. Nennecke

Krebsregister Schleswig-Holstein: A. Katalinic, U. Kunze

\section{REFERENCES}

[1] Beckmann MW, Jap D, Huschel B, et al. Wirkmechanismen ovarieller steroidhormone und antiöstrogene in der karzinogenese der mamma und des endometrium. Geburth Frauenheilk 2000; 60: 716.

[2] Writing Group for the Women's Health Initiative Investigators. Risks and benefit of estrogen plus progestin in healthy postmenopausal women. JAMA 2002; 288: 321-33.

[3. The Women's Health Initiative Steering Committee. Effects of conjugated equine estrogen in postmenopausal women with hysterectomy. JAMA 2004; 291: 31701-12.

[4] Heinemann LAJ, Lewis MA, Kühl-Habich D, et al. Lifetime history of oral contraceptive use and development of cancer of the uterus and ovary. Geburtshilfe Frauenheilkd 2002; 62: 566-73.

[5] Heinemann LAJ, Lewis MA, Kühl-Habich D, Braendle W, Möhner S. Use of oral contraceptives and risk of cancer of the uterus or ovary. Two case-control studies. Geburth Frauenheilk 2003; 63: 1018-26.

[6] Hempling R, Wong C, Piver S, Natarajan N, Mettlin C. Hormone replacement therapy as a risk factor for epithelian ovarian cancer: results of a case-control study. Obstet Gynecol 1997; 89: 1012-16.

[7] Persson I. Cancer risk in women receiving estrogen-progestin replacement therapy. Maturitas 1996; 23 (suppl): S37-45.

[8] Lacey JV, Mink PJ, Lubin J1, et al. Menopausal hormone replacement therapy and risk of ovarian cancer. JAMA 2002; 288: 334-41.

[9] Whittemore AS, Harris R, Intyre J and the Collaborative Ovarian Cancer Group. Characteristics relating to ovarian cancer risk: Collaborative analysis of 12 US caser-control studies. II. Invasive epithelial cancers in white women. Am J Epidemiol 1992; 136: 1184-203.

[10] Negri E, Tzanou A, Beral V, et al. Hormonal therapy for Menopause and ovarian cancer in a collaborative re-analysis of European studies. Int J Cancer 1999; 80: 848-51.

[11] Brekelmans CT. Risk factors and risk reduction of breast and ovarian cancer. Curr Opin Obstet Gynecol 2003; 15: 63-8.

[12] La Vecchia C, Brinton LA, McTiernan A. Menopause, hormone replacement therapy and cancer. Maturitas 2001;39: 97-115.

[13] Burger CW, Koomen I, Peters NAJB, Van Leeuwen FE, Kenemans P. Postmenopausal hormone replacement therapy and cancer of the female genital tract and breast. Eur Menop J 1997; 4: 23-36.

[14] Shapiro S. Adverse neoplastic and cardiovascular outcomes of HRT: the validity of the evidence. Endocrine 2004; 24: 203-10.

[15] Bakken K, Alsaker E, Eggen AE, Lund E. Hormone replacement therapy and incidence of hormone-dependent cancers in the Norwegian Women and Cancer study. Int J Cancer 2004; 112: 130-4.

[16] Sismondi P, Biglia N. HRT and gynaecologic cancer after WHI: old stuff or new doubts? Maturitas 2004; 48:13-8. 
[17] Mahavni V, Sood AK. Hormone replacement therapy and cancer risk. Curr Opin Oncol 2001; 13: 384-9.

[18] Pike MC, Ross RK. Progestins and menopause: epidemiological studies of risks of endometrial and breast cancer. Steroids 2000; 65: 659-64.

[19] Beral V, Million Women Study Collaborators. Ovarian Cancer and hormone replacement therapy in the Million Women Study. Lancet 2007; 369: 1703-10.

[20] WHO and International Agency for Research in Cancer. Combined estrogen-progestogen contraceptives and combined estrogenprogestogen menopausal therapy. IARC Monographs on the Evaluation of Carcinogenic Risks to Humans 2008; 91:( $\mathrm{http}: / /$ monographs.iarc.fr/ENG/recetpub/mono91.pdf)

[21] International Menopause Society (Ed. Birkhäuser MH, Barlow DH, Notelvitz M, Rees MC). Health plan for the adult woman. Taylor \& Francis, UK 2005; 131-34.

[22] Dinger JC, Heinemann LAJ, Möhner S, Do Minh Thai, Assmann A. Breast cancer risk associated with different HRT formulations: A register-based case-control study. BMC Women's Health 2006; 6: 13. www.biomedcentral.com/1472-6874/6/13.

[23] International Agency for Research on Cancer (Ed. Parkin DM, Whelan SLO, Ferlay J, Teppo L, Thomas DB) (WHO). Cancer incidence in five continents. 2002; Volume VIII. IARC Scientific Publications No. 155, Lyon 2002.

[24] American Institute for Cancer Research: Food, nutrition and the prevention of cancer: a global perspective. Ovary (p 288-293). World Cancer Research Fund and American Institute of Cancer Research, Washington (USA) DC 20009, ISBN: 1899533052.

[25] Dietel M, Lewis MA, Shapiro S. Hormone replacement therapy: pathobiological aspects of hormone-sensitive cancers in women relevant to epidemiological studies on HRT: a mini-review. Hum Reprod 2005; 20: 2052-60.

[26] Risch HA. Hormone replacement therapy and the risk of ovarian cancer. Gynecol Oncol 2002; 86: 115-7.

[27] Soegaard M, Jensen A, Hogdall E, et al. Risk factors for epithelial ovarian cancer overall and according to histological subtype [abstract ]. The XVIII FIGO World Congress of Gynecology \& Obstetrics 2006; Abstr FC2.14.5.

[28] Horn LC, Dietel M, Einenkel J. Hormone replacement therapy (HRT) and endometrial morphology under consideration of the different molecular pathways in endometrial carcinogenesis. Eur J Obstet Gynecol Reprod Biol 2005; 122: 4-12.
[29] Heinemann LAJ. WHI Studie und Million Women Study aus epidemiologischer Sicht. Frauenarzt 2004; 45: 217-22.

[30. Shapiro S. Risk of estrogen plus progestin therapy: a sensitivity analysis of findings in the Women's Health Initiative randomized controlled trial. Climacteric 2003; 6: 302-10.

[31] Dinger J, Heinemann LAJ, Do Minh Thai, et al. The risk of gynaecological cancers associated with different HRT formulations. A nested case-control study in the German Cohort Study on Women's Health. Geburtshilfe Frauenheilkd 2006; 66: 145-55.

[32] Schneider HP. HRT and cancer risks. Maturitas 2002; 43: S35-52.

[33] Kaufman DW, Kelly JP, Welch WR, et al. Noncontraceptive estrogen use and epithelial ovarian cancer. Am J Epidemiol 1989; 130: $1142-51$.

[34] Rodriguez C, Calle EE, Coates RJ, et al. Estrogen replacement therapy and fatal ovarian cancer. Amer J Epidemiol 1995; 141: 828-35.

[35] Hulley S, Furberg C, Barrett-Connor E, et al. Noncardiovascular disease outcomes during 6.8 years of hormone therapy: Heart and Estrogen/progestin Replacement Study follow-up (HERS II). JAMA 2002; 288: 58-66.

[36] Grady D, Gebretsadik T, Kerlikowske K, Ernster V, Petitti D. Hormone replacement therapy and endometrial cancer risk: a metaanalysis. Obstet Gynecol 1995; 85: 304-13.

[37] Persson I. Cancer risk in women receiving estrogen-progestin replacement therapy. Maturitas 1996; 23: S37-45.

[38] Rabe T, Vladescu E, Heinemann L, von Holst T. Endometriumkarzinom. OC, HRT, und Tamoxifen. Onkologe 1999; 5: 432-43.

[39] La Vecchia C, Brinton LA, McTiernan A. Menopause, hormone replacement therapy and cancer. Maturitas 2001;39: 97-115.

[40] Garbe E, Heinemann LAJ. Nichtkontrazeptiver Nutzen der Pille ein oft unbeachteter Fakt. Eine Übersicht zum gegenwärtigen Wissensstand. Zentralbl Gynakol 2000; 122: 18-27.

[41] Dinger J, Heinemann LAJ, Do Minh Thai, et al. The risk of gynaecological cancers associated with different HRT formulations. A nested case-control study in the German Cohort Study on Women's Health. Geburtshilfe Frauenheild 2006; 66: 145-55.

[42] Beral V, Bull D, Reeves G, Million Women Study Collaborators. Endometrial cancer and hormone-replacement therapy in the Million Women Study. Lancet 2005; 365: 1543-51.

[43] Lethaby A, Farquhar C, Sarkis A, et al. Hormone replacement therapy in postmenopausal women: endometrial hyperplasia and irregular bleeding (Cochrane Review). In: The Cochrane Library, Issue 4, 2000. Oxford: Update Software.

Received: April 2, 2008

Revised: May 15, 2008

Accepted: May 23, 2008

(C) Chen et al.; Licensee Bentham Open.

This is an open access article distributed under the terms of the Creative Commons Attribution License (http://creativecommons.org/licenses/by/2.5/), which permits unrestrictive use, distribution, and reproduction in any medium, provided the original work is properly cited. 